\title{
LA ORDEN DE ALEJAMIENTO EN LA VIOLENCIA INTRAFAMILIAR Y LA RELEVANCIA DEL CONSENTIMIENTO DE LA VÍCTIMA EN SU QUEBRANTAMIENTO
}

\author{
THE RESTRAINING ORDER IN DOMESTIC VIOLENCE AND THE RELEVANCE OF \\ THE VICTIM'S CONSENT IN INFRINGEMENTS.
}

Germán Varas Cicarelli ${ }^{1}$

Fecha de Recepción20/09/2011

Fecha de Aceptaciónt 4/03/2012

\begin{abstract}
RESUMEN
La ejecución y fiscalización de la medida de alejamiento en violencia intrafamiliar presenta variados problemas jurídicos y administrativos que diariamente jueces, fiscales y policías deben afrontar. Ciertamente que una mayor exigencia en la justificación del pronunciamiento de la medida y una regulación normativa más perfeccionada en cuanto ceda a la utilización de instrumentos tecnológicos y permita fijar una distancia mínima de seguridad para la víctima, son elementos que constituyen un avance significativo en la superación de los inconvenientes. Se observan además dificultades respecto a la vigencia de la medida de alejamiento frente a la impugnación de la sentencia que la dispuso, así como también si la vigencia de la misma como medida cautelar durante el procedimiento puede servir de abono a la pena definitiva de alejamiento que se disponga en la sentencia de término. Por último, la relevancia jurídica de la voluntad de aproximación de la víctima en el seno de una orden de alejamiento y la problemática precisa que se observa con la interpretación que debe darse al ilícito de desacato del artículo 240 del Código de Procedimiento Civil, obligan a profundizar las características propias que en la violencia intrafamiliar este delito presenta, adentrándonos a una interpretación más integral que ayude a flexibilizar la reacción penal ante la constatación del incumplimiento de la medida tolerada y/o aceptada por la víctima.
\end{abstract}

Palabras clave Orden de alejamiento, medida cautelar, pena accesoria, quebrantamiento de la orden de alejamiento, delito de desacato, relevancia del consentimiento de la víctima.

\footnotetext{
Abogado. Magíster en Derecho, Universidad de Génova, Italia. Juez Titular Tribunal de Juicio Oral en
} lo Penal de Angol, Chile. E.-mail: gvaras@pjud.cl

doi: 10.7770/RCHDYCP-V3N1-ART347 


\begin{abstract}
The execution and supervision of a restraining order in cases of Domestic Violence present various legal and administrative problems which judges, prosecutors and police forces have to deal with daily. Certainly, stricter requirements to justify the pronouncement of such orders and better regulations on agreement over the use of technological tools and fixing the minimum safety distance for the victim constitute significant progress in overcoming these problems. But difficulties are also found in monitoring compliance with the restraining order when the sentence under which it was issued is impugned, and in deciding whether its issue as a cautionary measure during proceedings may be set towards the period of restraint handed down in the final sentence. Finally the legal relevance of the victim's willingness to countenance an approach when protected by a restraining order, and the precise problem observed in the appropriate interpretation of contempt of article 240 of the Civil Proceedings Code, make it necessary to go more deeply into the particular characteristics which this offence presents in situations of domestic violence, to develop a more integrated interpretation which will help to make the law more flexible in reacting to infringement of an order when tolerated and/or accepted by the victim.
\end{abstract}

Key words: Restraining order, injunction, penalty, violation of restraining order, failure contempt, relevance of the victim's consent in breach of the expulsion order

Al igual que otras legislaciones comparadas que sancionan la violencia doméstica, nuestras leyes 20.066 y 19.968 contemplan numerosas medidas de protección y accesorias en favor de la víctima. Entre estas, la que a mi juicio resulta más problemática, en su ejecución práctica, es aquella que en España ${ }^{2}$ se conoce como orden de alejamiento y que en nuestro país aparece recogida y contemplada en el artículo $92 \mathrm{~N}^{\circ} 1$ de la ley 19.968 y artículo 9 letra b) de la ley 20.066; esta es, prohibir al agresor para acercarse a la víctima.

Al margen de la reciente normativa procesal, que regula la orden de alejamiento contemplada en los cuerpos legales antes citados, esta no es una medida que se haya introducido novedosamente con la entrada en vigencia del Código Procesal Penal y las leyes 20.066 y 19.968 , por cuanto a la entrada en vigencia de nuestra reforma procesal penal resultaba normal que, con ocasión de procesos seguidos por delitos de violencia de género $^{3}$, se impusiera como medida cautelar al ofensor formalizado la

2 Ley Orgánica 1/2004, de 28 de diciembre, de Medidas de Protección Integral contra la Violencia de Género.

3 Me refiero a violencia de género entendida no en sentido amplio, sino contra la violencia de género ceñida tan solo al ámbito familiar.

150 Revista Chilena de Derecho y Ciencia Política - ISSN Impreso: 0718-9389 / ISSN on line: 0719-2150 
prohibición de acercarse a la víctima. Lo anterior en aplicación de la medida cautelar del artículo 155 letra h) del Código Procesal Penal ${ }^{4}$.

Paradójicamente, para la violencia doméstica no constitutiva de delito, ya a mediados de la década de los 90 existió una incipiente preocupación legislativa que desembocó en la promulgación y entrada en vigencia de la ley 19.325, que introdujo una serie de mínimas garantías de protección para los afectados, en la que el juez -teniendo en cuenta la gravedad de los hechos- facultativamente podía decretar toda y cualquier medida precautoria destinada a garantizar la seguridad física o psíquica del afectado y la tranquila convivencia, subsistencia económica e integridad patrimonial del núcleo familiar, pudiendo incluso prohibir, restringir o limitar la presencia del ofensor en el hogar común, contexto donde cabe enmarcar la posibilidad implícita de decretar el alejamiento del agresor respecto de la víctima como medida precautoria innovativa.

Para comenzar estas reflexiones, desde ya debo indicar que en materia de violencia intrafamiliar el alejamiento decretado como medida cautelar o bien como pena accesoria tiene como finalidad alejar al agresor del contexto social en el que ha nacido la ocasión del delito, eliminando una ulterior repetición de la agresión. Su imposición presume que la proximidad entre el agresor y su víctima, una vez cometido algún hecho constitutivo de violencia intrafamiliar, es objetivamente peligrosa.

Para una mejor compresión y claridad de los temas que pretendo abordar, es necesario sistematizar las distintas perspectivas procesales que, judicialmente, el alejamiento puede adoptar en la tramitación de un proceso por violencia intrafamiliar, sea o no constitutivo de delito. En efecto, la tramitación de un procedimiento judicial por violencia intrafamiliar puede dar lugar a la emisión de diversos tipos de orden de alejamiento o, mejor, a la emisión de órdenes de alejamiento de diversa naturaleza que se dictarán en momentos procesales diferentes y que -como posteriormente se dirá- traerán consecuencias jurídicas diferentes en caso de quebrantamientos por parte del agresor.

Dentro de este amplio abanico en el que se integran las distintas posibilidades de alejamiento y aplicando la misma sistemática contemplada por nuestro legislador que distingue la violencia intrafamiliar constitutiva de delito de aquella que no lo es, cabría distinguir en:

Solución no extensible después de dictada la sentencia de término al no contemplarse como pena accesoria hasta antes de la dictación de la ley 20.066, ni tampoco observada en el conocimiento de los delitos-faltas, quedando la víctima, por este motivo, totalmente desprotegida y abandonada a su suerte frente a otras agresiones por el ofensor. 


\section{Orden de alejamiento en violencia intrafamiliar constitutiva de delito.}

a.- El alejamiento que se dicta como medida cautelar personal en contra del imputado en cualquier etapa de la investigación.

a1. Antes de la formalización de la investigación ${ }^{5}$, conforme lo dispuesto en el artículo 9 letra c) de la ley 20.066.

a2. Después de la formalización de la investigación y hasta antes de la sentencia de término, conforme lo dispuesto en el artículo 9 letra c) de la ley 20.066 o de acuerdo a lo dispuesto en el artículo 155 letra g) del CPP.

a3. El alejamiento que se impone como condición al imputado para mantener la Suspensión Condicional del Procedimiento, conforme lo dispuesto en el artículo 9 letra c) de la ley 20.066 o de acuerdo a lo dispuesto en el artículo 155 letra g) del CPP.

b.- El alejamiento impuesto como pena accesoria, conforme a nuestro actual artículo 9 letra c) de la ley $20.066^{6}$.

\section{Orden de alejamiento en violencia intrafamiliar no constitu- tiva de delito.}

a. El alejamiento que se dicta como medida cautelar en protección de la víctima en cualquier etapa del procedimiento por violencia intrafamiliar no constitutiva de delito, conforme lo dispuesto en el artículo $92 \mathrm{~N}^{\circ} 1$ de la ley 19.968.

b. El alejamiento impuesto como condición al denunciado para mantener la suspensión condicional de la dictación de la sentencia ${ }^{7}$, conforme lo dispuesto en el artículo 94 letra b) de la ley 19.968 en relación con el artículo $92 \mathrm{~N}^{\circ} 1$ del mismo cuerpo legal.

c. El alejamiento impuesto como sanción accesoria conforme a nuestro actual artículo 9 letra c) de la ley 20.066.

5 Conforme reza el artículo 15 de la ley 20.066, y de forma excepcional en nuestra legislación, es posible decretar medidas cautelares en contra del encartado aun antes de la formalización de la investigación.

6 Esta modalidad en que puede presentarse la medida de alejamiento -pena accesoria- es facultativa para el juez, por cuanto la exigencia establecida en el citado artículo 9 se satisface con la sola imposición de cualquiera de las medidas accesorias que allí aparecen indicadas.

7 De conformidad con lo dispuesto en el artículo 96 de la ley 19.968 que crea los Tribunales de Familia.

152 Revista Chilena de Derecho y Ciencia Política - ISSN Impreso: 0718-9389 / ISSN on line: 0719-2150 
d. Y, por último, el alejamiento impuesto como única sanción principal en la propia sentencia. No obstante, tal hipótesis no está disponible en nuestra legislación, atento lo dispuesto en el artículo 8 de la ley 20.066 que castiga siempre el maltrato constitutivo de violencia intrafamiliar no constitutiva de delito, atendida su gravedad, con una multa de media a quince unidades tributarias mensuales ${ }^{8}$.

Su aplicación como medida de protección es facultativa para el juez toda vez que siempre en un proceso por violencia intrafamiliar puede estimar que la protección de la víctima y de su grupo familiar se satisface con cualquiera de otras medidas $^{9}$ establecidas en los artículos 92 de la ley 19.968. Asimismo, también es facultativa su aplicación como pena o sanción ${ }^{10}$ accesoria por cuanto el artículo $9^{11}$ de la ley 20.066 otorga al juez la posibilidad de elegir entre cualquiera otra de las que allí se estatuyen.

Este carácter potestativo de la orden de alejamiento entregado a la libre valoración judicial sobre la necesidad de decretarlo en desmedro de su mantención como obligatorio, así como la falta de obligatoriedad de decretar conjuntamente la prohibición de comunicación ${ }^{12}$ entre el agresor y la víctima, puede ser merecedor de críticas atendido el carácter de la violencia doméstica, pero a mi modo de ver resulta ser la aplicación más aconsejable teniendo en cuenta precisamente que afecta a personas integradas en el ámbito familiar o que mantienen o han mantenido una relación sentimental donde el perdón y la reconciliación no son fenómenos desconocidos.

8 Esta circunstancia, a mi juicio, sin duda que merece críticas por cuanto no se observa en qué medida una pena de multa pueda efectivamente ser disuasiva o resocializadora para el infractor en cuanto a no reincidir en su acción ilícita. Máxime cuando en la ponderación de la sanción para el caso concreto el juez puede estimar que la menos indicada sea el pago de una prestación económica por el infractor, sino que por el contrario, sea necesaria, proporcional y conducente a los objetivos buscados otra sanción que efectivamente puede contribuir a la mejora en las relaciones familiares.

9 Artículo 92. Medidas cautelares en protección de la víctima. El juez de familia deberá dar protección a la víctima y al grupo familiar. (...) Para tal efecto, en el ejercicio de su potestad cautelar (...), podrá adoptar una o más de las siguientes: 1 . Prohibir al ofensor acercarse a la víctima y prohibir o restringir la presencia de aquél en el hogar común y en el domicilio, lugar de estudios o de trabajo de ésta, así como en cualquier otro lugar en que la víctima permanezca, concurra o visite habitualmente. (...).

10 Me refiero a aquella que sea o no constitutiva de delito.

11 Artículo 9. Medidas accesorias. Además de lo dispuesto en el artículo precedente, el juez deberá aplicar en la sentencia una o más de las siguientes medidas accesorias: a) Obligación de abandonar el ofensor el hogar que comparte con la víctima. b) Prohibición de acercarse a la víctima o a su domicilio, lugar de trabajo o estudio, así como a cualquier otro lugar al que ésta concurra o visite habitualmente. (...).

12 Con ello, se evitaría situaciones trágicas en las que decretando el alejamiento, el agresor sigue intimando impunemente a la víctima con la finalidad de restablecer contactos, mediante llamadas telefónicas, envió de mensajes al móvil, etc. 
Lejos de una actitud abstencionista de nuestra judicatura que pudiera estar dada precisamente por el carácter facultativo de la imposición de la orden de alejamiento, es posible observar una incorrecta y en muchos casos precipitada adopción judicial de la medida en la violencia intrafamiliar no constitutiva de delito e incoada en los nuevos Tribunales de Familia. Al efecto, sin contar con mayores antecedentes que no sea el relato indiciario de la víctima y sin precisarse en las resoluciones una motivación suficiente que pueda explicar la situación objetiva de riesgo que ella enfrenta, así como la proporcionalidad y necesidad para prevenir eventuales nuevos ataques a la ofendida, se está disponiendo temporalmente de la medida de alejamiento, acarreándose en muchos casos una aplicación desigual y discrecional en su concesión, y que, incluso, en muchos casos llega a afectar la libertad personal y ambulatoria del denunciado o imputado o a su derecho a fijar el lugar de su residencia.

Más aún, el problema se acrecienta cuando la medida de alejamiento viene impuesta como pena accesoria toda vez que nuestra legislación no faculta al juez ni al Tribunal para que en casos excepcionales, por ejemplo, una reconciliación de la pareja o una superación de la crisis el sentenciador pueda dejar sin efecto o suspender la imposición de tal pena. Máxime cuando puede darse el supuesto que la misma siga vigente una vez cumplida la pena principal pudiéndose plantear numerosos problemas de constitucionalidad al respecto. Al efecto, y sin perjuicio que los mismos no son materia de este trabajo, ellos pueden estar dados al vulnerarse principios de prohibición de la arbitrariedad de los poderes públicos, pues la actual regulación carece de explicación racional; de personalidad de las penas, pues se impone a la propia víctima o persona protegida; de legalidad, pues la víctima o persona protegida no ha cometido delito alguno, así como del derecho al libre desarrollo de la personalidad, al impedir a la víctima o persona protegida a acercarse al cónyuge o compañero; a la libertad, pues se le impide autodeterminarse personalmente; a la dignidad de la persona, no respetándose su vida privada; así como al derecho a la tutela efectiva, pues la víctima o persona protegida no puede defenderse ante la imposición de la pena.

Tales circunstancias ameritan contener en nuestra legislación alguna norma que permita al sentenciador suspender o dejar sin efecto la medida de alejamiento impuesto como pena, toda vez que su imposición -teniendo en cuenta su finalidad- resultaría fácil de deshacer si efectivamente se acredita el término de la situación de riesgo que la motivó.

Ausencia normativa de una distancia mínima de seguridad en la medida de alejamiento.

Asimismo, ninguna de nuestras normas jurídicas que establecen la medida de alejamiento permite al juez fijar una distancia mínima entre el agresor y la persona protegida que no se podrá rebasar. Sin embargo, en algunos casos esta indeterminación es perfeccionada por el órgano jurisdiccional al fijar -al momento de decretar la

154 Revista Chilena de Derecho y Ciencia Política - ISSN Impreso: 0718-9389 / ISSN on line: 0719-2150 
medida de alejamiento- la distancia mínima a observar, circunstancia última que viene a confirmar la importancia de este elemento en la ejecución práctica de la medida en comento.

Lo que quiero resaltar en este punto es la ausencia del tipo normativo que establezca la imposición de esta distancia mínima de seguridad entre la víctima y el agresor, es decir, no me refiero a la distancia concreta, sino que a la medida que obliga a acordarla, por cuanto para fijar la distancia mínima que ha de mediar entre la víctima y el agresor, el juez deberá huir de cualquier tendencia al automatismo y valorar, en cada caso concreto, no solo la situación de riesgo objetivo en la que se encuentre la víctima sino que también otros parámetros con los que pueda contar, como, por ejemplo, el grado de afectación psicológica de la víctima que, eventualmente, haga recomendable una distancia de seguridad mayor.

Así las cosas, y al igual que legislaciones $\operatorname{comparadas}^{13}$ que han regulado esta materia, convendría considerar en el texto legal una distancia mínima entendida como meramente orientativa y, por tanto, la misma podría ser incrementada o incluso, en excepcionales supuestos, disminuida, teniendo siempre presente que la finalidad perseguida es asegurar un círculo de protección física a la víctima y la confrontación visual entre ella y su agresor, circunstancias en la que descansa el elemento a valorar por la autoridad judicial, por cuanto la convierte en una norma de observación perceptiva en todo alejamiento que se decrete y sin duda facilita su fiscalización y ejecución práctica. A modo de ejemplo, una distancia mínima de 500 metros constituiría un ámbito espacial suficiente para asegurar y permitir una rápida respuesta policial, además de garantizar la imposibilidad de contactos visuales con el ofensor y la prevención y repetición de nuevos daños. Sin embargo, sin una voluntad efectiva de fiscalización ninguna mayor distancia supone un mayor control a la hora de cumplirse la medida.

\section{Ausencia normativa en la regulación de la utilización de instrumentos tecnológicos para el control del cumplimiento.}

Otra insuficiencia anotada de nuestros cuerpos normativos respecto de la medida de alejamiento se refiere a la posibilidad de utilizar instrumentos tecnológicos adecuados para verificar de inmediato su cumplimiento y que, normalmente, hoy están adoptando la forma de pulseras con tecnología de localización GPS incorporada en la persona del agresor, que permite conocer su ubicación de manera permanente. En honor a la verdad, en nuestra legislación no existe ninguna norma que posibilite el

13 Protocolo de Actuación de las Fuerzas y Cuerpos de Seguridad y de Coordinación con los Órganos Judiciales para la protección de las Víctimas de la Violencia Doméstica y de Género, aprobado el 28 de junio de 2005, "Disponible en la World Wide Web: http://porderjudicial.es". 
control de una pena utilizando instrumentos tecnológicos, ni menos en su aplicación para medidas cautelares de protección dispuestas durante la tramitación de algún proceso por violencia intrafamiliar constitutiva o no de delito. Sin embargo, pronto a convertirse en ley descansan en nuestro Congreso Nacional los proyectos de ley ${ }^{14}$ que introducen modificaciones a la ley 18.216 sobre medidas alternativas para el cumplimiento de penas privativas o restrictivas de la libertad y al Código Procesal Penal, incorporando un sistema de vigilancia y control electrónico de personas. El primero de ellos agrega al artículo $30^{15}$ inciso 1 de la ley 18.216, la frase final siguiente: "Para garantizar el cumplimiento de esta condición, el tribunal podrá imponer al beneficiado el uso de un dispositivo de vigilancia y control tecnológico que permita su ubicación permanente por todo el tiempo de duración de la medida respectiva". Por su parte, el segundo de los proyectos -entre otras modificaciones al Código Procesal Penal- agrega al artículo $155^{16}$ inciso 2 la siguiente frase final: "Adicionalmente, como medida complementaria, podrá imponer al imputado el uso de un dispositivo de vigilancia y control tecnológico que permita su ubicación permanente durante el tiempo que duren las medidas cautelares dispuestas". Asimismo, agrega al artículo $238^{17}$ el siguiente nuevo inciso 2, pasando el actual 2 a ser 3 y final: "Para asegurar el cumplimiento de una o más de las condiciones anteriores, el juez de garantía podrá imponer al imputado el uso de un dispositivo de vigilancia y control tecnológico que permita su ubicación permanente durante el período de suspensión".

Teniendo presente la finalidad de la medida de alejamiento, el dispositivo electrónico resulta ser una herramienta eficaz para la protección de la víctima, por cuanto al vigilar y controlar los movimientos de su agresor, emitiendo una alerta si este altera su rutina o ingresa a un área prohibida, además de poder garantizar lo resuelto por el Tribunal, es un medio disuasivo para prevenir nuevos ataques de esta naturaleza.

Ahora bien, conforme a la actual redacción de los proyectos de ley, la utilización de tales instrumentos será siempre potestativa y discrecional, es decir, queda entregada a la decisión judicial la procedencia o no de su utilización en cada caso concreto. En efecto, la utilización de tales instrumentos ciertamente que tiene una sustantividad híbrida por cuanto no solo se protegerá a la víctima haciendo más

14 Véase en boletines № 6613/2007 y Nº612/2007, respectivamente. Cuya etapa de tramitación descansa en un primer trámite constitucional.

15 Artículo 30 inciso 1 ley 18.216 que establece medidas que indica como alternativas a las penas privativas de libertad o restrictivas de libertad.

16 Artículo 155 inc. $2^{\circ}$. El tribunal podrá imponer una o más de estas medidas según resultare adecuado al caso y ordenará las actuaciones y comunicaciones necesarias para garantizar su cumplimiento.

17 Artículo 238. Condiciones por cumplir decretada la suspensión condicional del procedimiento. El juez de garantía dispondrá, (...) de una o más de las siguientes condiciones: a) Residir o no residir en un lugar determinado; b) Abstenerse de frecuentar determinados lugares o personas; (...).

Durante el período de suspensión y oyendo en una audiencia a todos los intervinientes que concurrieren a ella, el juez podrá modificar una o más de las condiciones impuestas. 
eficaz el cumplimiento de la orden de alejamiento, sino que además su imposición afecta a los derechos y libertades del individuo al interferir en su esfera privada ${ }^{18}$. Por tales motivos deberá ponderar en consecuencia el órgano jurisdiccional la situación de riesgo objetivo que da origen a la orden de alejamiento para disponer la utilización de tal instrumento.

Por otro lado, desde una perspectiva práctica, la utilización de tales instrumentos supone una efectiva y notable descarga de trabajo para las fuerzas y órganos de seguridad encargados de la fiscalización de las órdenes de alejamiento al contar con instrumentos que les permitirán actuar en los casos estrictamente necesarios, haciendo sin duda más efectiva sus funciones en la debida protección a la víctima.

Así las cosas, un factor que debe ser considerado en la ponderación judicial que autorice su imposición es la pronta opinión que los órganos policiales puedan entregar en cuanto a la intensidad y medidas de control a utilizar en función del riesgo objetivo del caso concreto, así como también los aportes que puedan realizar los órganos públicos que tienen por misión velar por la efectiva tutela institucional de la violencia doméstica.

\section{Vigencia de la orden de alejamiento frente a la impugnación de la sentencia.}

Al margen de las insuficiencias normativas antes anotadas, otros de los problemas advertidos se refiere a la existencia de lagunas normativas que provocan un estado de completa incertidumbre respecto a si debe entenderse vigente la orden de alejamiento -dispuesta inicialmente en la sentencia definitiva de un proceso por violencia intrafamiliar constitutivo de delito-, mientras pende la resolución del recurso que impugnó la sentencia que la instaló. Para una mejor comprensión del caso que origina el problema, expondré el siguiente ejemplo: supongamos que durante la tramitación de un proceso por violencia intrafamiliar constitutivo de delito no se decretó provisionalmente la medida de protección cautelar de alejamiento en contra del imputado. Sin embargo, recién en la sentencia definitiva se impone en contra del imputado como pena accesoria la de alejamiento por el término de dos años. No contento con esta pena accesoria y ni con la pena principal, el acusado o la víctima interponen un recurso procesal en contra de la sentencia.

Esta situación lleva a concluir que el efecto suspensivo del recurso de apelación o de nulidad supondrá dejar sin efecto la medida de alejamiento con el consiguiente riesgo que ello provocará para la seguridad de la víctima.

18 Ciertamente que en este punto se abre un problema constitucional no menor que no pretendo abordar en este trabajo. 
En tal caso y a fin de mitigar la situación de riesgo que se provocaría a la víctima mientras transcurre el termino de impugnación de la sentencia, el juez, de oficio o a petición del órgano persecutor, conforme lo dispuesto en el artículo 122 del Código Procesal Penal, en relación al artículo 155 del mismo Código adjetivo, debiera decretar una medida cautelar de alejamiento en un resolución pronunciada inmediatamente después de la comunicación del veredicto o inmediatamente antes a la sentencia o en la misma sentencia definitiva. Aun cuando pudiese ser discutible esta fórmula para casos de procedimientos simplificados regulados en el Libro IV, Título I del Código Procesal Penal ${ }^{19}$, la solución podría ser entregada conforme la norma del artículo $15^{20}$ de la ley 20.066 que permite al juez decretar medidas cautelares en favor de la víctima en cualquier etapa del procedimiento e incluso aún antes de la formalización, puesto que precisamente esta norma mantiene como finalidad evitar que durante la tramitación del proceso la víctima quede desprotegida. Así las cosas, es perfectamente sostenible disponer de la medida de protección justo antes del fallo o en la misma sentencia y mantener su vigencia mientras dure la tramitación del recurso y hasta que esta sea definitiva.

El tiempo que ha durado la medida de alejamiento, ¿puede ser descontada al que se imponga en la sentencia definitiva?

Otro asunto que no ha resultado pacífico y que conforme a mi experiencia como juez con competencia penal en el sur de Chile no ha resultado de mayor interés en los tribunales donde me ha tocado intervenir, hace referencia en que si el período que ha durado el alejamiento impuesto como medida de protección durante el procedimiento, debe descontarse del tiempo de alejamiento que como pena accesoria se imponga en la sentencia definitiva de un proceso por violencia intrafamiliar, sea o no constitutiva de delito. Ahora bien, la posición que se acoja en este caso puede depender del significado jurídico penal que se dé a la medida durante el proceso. Al efecto, si consideramos que la medida de alejamiento se hizo necesaria en razón del riesgo objetivo por el que atravesaba la víctima, de forma alguna cabría descontar el tiempo que ha durado a la pena accesoria de alejamiento dispuesta en la sentencia definitiva, al no ser homologable una medida de protección a una pena que pudiere imponerse en una sentencia definitiva. Al efecto, podríamos sostener que las medidas de protección no tienen el carácter de pena, ni son instrumentales en relación con el acusado, ni con las finalidades perseguidas con el procedimiento; es decir, no se acuerdan con la finalidad cautelar que pueda dictarse y ejecutarse la ulterior

19 En los que existe vasta jurisprudencia que no hace procedente la aplicación de las medidas cautelares del artículo 155 del Código Procesal Penal.

20 Medidas Cautelares. En cualquier etapa de la investigación o del procedimiento sobre delitos constitutivos de violencia intrafamiliar, y aún antes de la formalización, el tribunal (...) podrá decretar las medidas cautelares que sean necesarias para proteger a la víctima (...). 
sentencia. Así, su carácter protector, exclusivamente dirigido a la víctima, impediría homologarla a la pena que eventualmente se pudiera imponer, a fin de descontar de la misma ese tiempo de alejamiento trascurrido.

Por el contrario, si consideramos que la medida de alejamiento es una medida cautelar, el razonamiento anterior no tiene sustento, y resultaría procedente descontar el tiempo que ha durado a la pena accesoria de alejamiento que se imponga en la sentencia de termino.

En mi opinión la medida de alejamiento impuesta durante el proceso tiene una naturaleza jurídica híbrida por cuanto persigue finalidades distintas y con efectos en varios ámbitos del proceso. En efecto, esta puede ser calificada como una medida cautelar personal por cuanto directamente, en su esencia, es un instrumento que restringe verdaderamente derechos fundamentales del imputado al verse limitada su libertad de desplazamiento y circulación con su imposición, especialmente, los sitios a los que puede acudir así como las personas con las que se relaciona, y, asimismo, la orden de alejamiento persigue proteger a la víctima del peligro de reiteración de agresiones similares y de evitar la reproducción de situaciones de proximidad personal entre el agresor y la ofendida que pudieran propiciar tal reiteración u otros incidentes.

En conclusión, es posible anotar que el acto procesal de su imposición no tiene un único propósito, por el contrario, presenta dos marcadas características que lo hacen multifuncional al determinar una efectiva restricción al derecho fundamental del individuo a la libre deambulación y una finalidad específica preventiva en función de dar protección a la víctima impidiendo que prosigan o se cometan nuevos hechos delictivos sobre su persona o entorno. A mayor abundamiento, y acudiendo a un argumento sistemático es posible demostrar y comprobar la argumentación anterior al encontrarse inserta la medida de alejamiento bajo artículos que asimilan los términos medidas de protección y medidas cautelares ${ }^{21}$. Así las cosas, el problema planteado en este punto no deja dudas que siempre procederá homologarla a la pena que eventualmente se pudiera imponer, a fin de descontar de la misma ese tiempo de alejamiento trascurrido.

21 Artículo 92 de la ley 19.962 titulado medidas cautelares en protección a la víctima y artículo 7 de la ley 20.066 que estatuye "Cuando exista una situación de riesgo inminente (...), el tribunal, con el solo mérito de la denuncia, deberá adoptar las medidas de protección o cautelares que corresponda". 
El quebrantamiento de la orden de alejamiento o prohibición de acercamiento a la víctima.

El constante ingreso de denuncias por el delito de desacato de la orden de alejamiento ${ }^{22}$ resulta ser una constante que hoy en día deben enfrentar los organismos que intervienen en materia judicial. Al efecto, y sin perjuicio de que el quebrantamiento mismo de la orden de alejamiento puede ser abordado como otra forma autónoma de violencia contra la mujer en la modalidad de acechó a la víctima con la finalidad de restablecer contacto, lo cierto es que esta problemática conlleva a un multiplicidad de situaciones fácticas y jurídicas a las que puede derivar el conflicto conyugal en la que la víctima ha sido objeto de maltrato físico o psicológico.

No resulta redundante indicar que uno de los factores que pueden explicar el quebrantamiento de la medida de alejamiento descansa en el fenómeno de la violencia doméstica. Al efecto, sabido es el carácter cíclico $^{23}$ del conflicto que afecta a las mujeres víctimas de la violencia doméstica, en que se distingue la fase de acumulación de la tensión -caracterizado por una actitud hostil del sujeto activo (hombre), aumento de las discusiones e intolerancia a todo lo que hace el sujeto pasivo de la violencia (mujer)-, la fase de la agresión -caracterizada por la manifestación de la violencia psíquica, física o sexual-, y la fase de la reconciliación -caracterizada por el arrepentimiento del sujeto activo y la petición de perdón a la mujer con todo tipo de promesas que auguran un cambio de su conducta-. Este mismo carácter cíclico de la violencia que nos aparece construido sobre la base de la violencia habitual desembocará en una nueva agresión y provocará, por ende, el quebrantamiento de cualquier medida de alejamiento que se pueda disponer.

Otros casos que explican el quebrantamiento, es la irritación del agresor motivada por la denuncia interpuesta en su contra y los efectos jurídicos que le ocasiona en su persona una sentencia condenatoria, lo que le lleva a aproximarse a la víctima con el único fin de repetir la agresión.

Asimismo, sencillamente el quebrantamiento de la orden de alejamiento se puede provocar a través de un comportamiento repetido e intrusivo de acecho con el que el agresor pretende restablecer el contacto personal contra la voluntad de la víctima ${ }^{24}$. O bien, es la especial situación de vulnerabilidad económica, inestabilidad

22 Orden de alejamiento en cualquiera de sus modalidades ya se trate de pena accesoria o medidas de protección o cautelar.

23 Walker, Eleonore, The Battered Woman, New York, United States, Springer, 1984. En el que describe el ciclo de la violencia.

24 Esta conducta es una clara manifestación de una forma específica de violencia de género contra mujeres, que en países anglosajones, como también Italia y España, cuenta con una regulación y tratamiento legal especifico, denominado Stalking. Ahora bien, el tratamiento especial de esta figura legal 
emocional y confusión por la que atraviesan las víctimas de violencia doméstica la que les lleva a tomar la iniciativa de aproximarse al agresor y en algunos casos reanudando la convivencia en una búsqueda frenética para lograr la estabilidad de su persona y, principalmente, de su núcleo familiar ${ }^{25}$.

Estas últimas situaciones provocan, en muchos casos, actos de violencia de género mucho más graves que un simple daño físico o psíquico de las mujeres víctimas de violencia de género, sino que son la causa de un alto porcentaje de femicidios.

\section{Consecuencias del incumplimiento de la medida de alejamiento.}

El incumplimiento de la medida de alejamiento, además de sancionársele con la medida de apremio (arresto hasta por 15 días), puede llegar a constituir el delito de desacato que se castiga conforme a la pena privativa de libertad señalada en el artículo 240 del Código de Procedimiento Civil.

Al efecto, el artículo 10 de la ley 20.066 así como el artículo 94 de la ley 19.986, no establecen un ilícito de desacato en sí, ya que tal se encuentra establecido en el artículo 240 inciso final del Código de Procedimiento Civil, tampoco ordena la aplicación inmediata de las penas que contempla la norma procesal civil en examen sino que tan solo regula el envío del caso al Ministerio Público con el objeto de que se determine si estamos en presencia o no de un delito de desacato, situación que, en definitiva, es resorte de la autoridad jurisdiccional. Así las cosas y a diferencia de lo sucedido en la legislación penal española a propósito de la entrada en vigencia de la LO 1/2004 que modificó el artículo 468.2 del Código Penal' ${ }^{26}$, nuestra legislación no contempla una figura típica que sancione especialmente el quebrantamiento de la prohibición de aproximación del ofensor a la víctima en un proceso seguido por violencia intrafamiliar (sea o no constitutiva de delito) ya sea impuesta como pena accesoria o medida cautelar. Al efecto, el quebrantamiento en análisis no aparece recogida en ninguna de las hipótesis fácticas descritas en el artículo 90 de nuestro Código Penal.

y su reproche sancionatorio descansa -entre otras razones- en argumentos políticos criminales preventivos, por cuanto la realidad ha mostrado que un porcentaje no menor de víctimas de femicidios $(76 \%$ según estadísticas de Stalking resource center. www.ncvc.org/src) ha sido precedido por conductas de este tipo.

25 Lorente Acosta, Miguel, Mi marido me pega lo normal: agresión a la mujer, realidades y mitos, Crítica, Barcelona, 2001.

26 De acuerdo al artículo 468.2 del Código Penal español modificado por la LO 1/2004 se castiga con la pena de prisión de seis meses a un año a los que quebrantaren una pena de las contempladas en el artículo 48 de mismo código o una medida cautelar o de seguridad de la misma naturaleza impuesta en procesos criminales en los que el ofendido sea alguna de las personas a las que se refiere el artículo 173.2 CP español). 
Casos de quebrantamientos de la orden de alejamiento que quedan excluidos de ser eventualmente sancionados con la pena establecida para el delito desacato por aplicación del principio de tipicidad del Derecho Penal

Sin embargo, habrá que precisar qué tipo de quebrantamientos de la orden de alejamiento hace aplicable la norma de reenvió y la imposición del arresto anotados por cuanto las distintas posibilidades que integran no las hacen alcanzable al universos de casos sistematizado al comienzo de este trabajo y contemplado por nuestro legislador para la violencia intrafamiliar.

Al efecto, no son subsumibles dentro del supuesto fáctico de la norma de reenvió del artículo 10 de la ley 20.066, ni en el de la imposición del arresto, los incumplimientos de la medida de alejamiento impuestos como medidas cautelares personales de conformidad con el artículo 155 letra g) del CPP y aquellos impuestos como condición para mantener la Suspensión Condicional del Procedimiento de conformidad con el artículo 238 letra b) del CPP. Al efecto, para estos casos nuestra jurisprudencia ha venido desestimando la existencia del delito desacato sobre la base de criterios de interpretación sistemáticos, tanto del artículo 240 del Código de Procedimiento Civil como del carácter de última ratio y subsidiario del Derecho Penal. Tales argumentos se sostienen en cuanto consideran que la medida de alejamiento del artículo 155 letra g) y del artículo 238 letra b) del Código Procesal Penal corresponde a aquellas resoluciones judiciales que condenan a una prestación de no hacer $^{27}$, respecto de las que existe un mecanismo normativo directo en caso de incumplimiento; función que cumple precisamente el artículo 141 y el artículo 238 del citado Código Procesal Penal; desestimándose, en consecuencia, la persecución del infractor por el delito de desacato por ser tal ilícito subsidiario y de aplicación restringida aquellas resoluciones judiciales que imponiendo obligaciones de no hacer su incumplimiento no se encuentra sancionado de un modo diferente, ya sea por vía material o procesal.

Reconozco eso sí que los casos que planteo resultan poco usuales por cuanto generalmente los fiscales al solicitar la medida de alejamiento como cautelar o como condición de la suspensión condicional del procedimiento lo hacen invocando el artículo 7 y artículo 9, respectivamente, de la ley 20.066, asegurándose de esta forma que cualquier incumplimiento puede llegar a dar origen al delito de desacato.

Sin embargo, en una interpretación teleológica de la medida de alejamiento impuesta como cautelar o condición de la suspensión condicional del procedimiento conforme lo dispuesto en los artículos 155 letra g) o 238 letra b), respectivamente, del Código Procesal Penal, y no en conformidad con las normas antes anotadas de la ley 20.066 sobre Violencia Intrafamiliar, no deberían existirían motivos para dar aplica-

27 Este punto es discutido, no obstante más adelante explicaré las razones que motivan a sostenerlo. 
ción a lo dispuesto en el artículo 10 de la ley 20.066 y sancionar al infractor por el delito de desacato, por cuanto la razón intrínseca que subyace en esta última norma es llegar a sancionar como tal cualquier quebrantamiento de la medida de alejamiento en procedimientos por violencia doméstica ceñida al ámbito familiar, no quedando reservada la misma a los supuestos en que se incumpliera el alejamiento o incomunicación decretados como pena accesoria en sentencia firme.

No obstante, la tendencia jurisprudencial antes indicada es acertada teniendo en cuenta el principio de tipicidad del derecho penal, principio que no permite realizar una interpretación analógica in malan partem llegando a considerar punible lo que la ley no penaliza con el ilícito establecido en el artículo 240 del Código de Procedimiento Civil. Al efecto, y sin ser redundante, las normas de reenvió antes anotadas -el artículo 10 de la ley 20.066 así como el artículo 94 de la ley 19.968- solo contemplan el reenvió al Ministerio Público del incumplimiento de la medida de alejamiento cuando ha sido impuesto de conformidad con lo dispuesto en los artículos 7 y 9 de la ley 20.066 o artículo 92 de la ley 19.968.

\section{Incumplimiento ordinario e incumplimiento consentido de la medida de alejamiento}

Despejado lo anterior conviene entrar de lleno al análisis de las particularidades propias que el incumplimiento de la medida de alejamiento en la violencia intrafamiliar presenta, especialmente, en cuanto a la relevancia jurídica de la voluntad de aproximación de la víctima en el seno de la orden de alejamiento y la problemática precisa que se observa con el delito de desacato del artículo 240 del Código de Procedimiento Civil. Finalizaré este trabajo tomando una postura sobre la interpretación más correcta que se debe tener en cuenta para la configuración del ilícito que sanciona su incumplimiento atento a las características propias que en la violencia doméstica este injusto presenta.

Previo al análisis propuesto conviene indicar que el delito de desacato mantiene una ubicación sistemática dentro del Título XIX del Libro Primero del Código de Procedimiento Civil, que trata de la ejecución de las resoluciones judiciales, cuyo párrafo primero, a su vez, se refiere a las resoluciones pronunciadas por tribunales chilenos, dentro del cual se establecen diversos mecanismos dirigidos a obtener su cumplimiento, encontrándose el artículo 240 que en su inciso $2^{\circ}$ preceptúa que: "El que quebrante lo ordenado cumplir será sancionado con reclusión menor en su grado medio a máximo", siendo esta disposición la que contempla el tipo penal que la doctrina conoce como incumplimiento de resoluciones judiciales o desacato.

No existe discusión respecto a que el bien jurídico protegido para el delito de desacato del artículo 240 del CPC es la correcta administración de justicia y el efectivo imperio de las resoluciones judiciales. 
Como lo ha resuelto nuestra jurisprudencia ${ }^{28}$ sobre la materia a propósito del delito de desacato en violencia intrafamiliar, "que se haya quebrantado lo ordenado cumplir, entendiéndose por esto, según la definición del diccionario de la Real Academia de la Lengua, la acción y efecto de quebrantar, acepción que no incluye conductas omisivas. De este modo, debe entenderse que la conducta sancionada solo incluye el incumplimiento de una obligación de no hacer ${ }^{\prime \prime 2}$, siendo de esta clase de obligaciones aquella en que consiste la medida accesoria o pena impuesta al encausado, en cuanto le estaba prohibido (no hacer) acercarse a la persona de la ofendida y/o a su domicilio.

De tal forma el tipo objetivo del artículo 240 del Código de Procedimiento Civil en lo que dice relación con el incumplimiento de la medida de alejamiento se satisface con el quebrantamiento de la prohibición de residir o acudir a determinados lugares, o en la prohibición de aproximarse a la víctima u otras personas determinadas, ya venga impuesto como pena accesoria o medida cautelar o de protección.

De entre las figuras de cuyo incumplimiento puede derivarse el delito de desacato, quizá la más discutida sea cuando la medida ha sido impuesta como medida cautelar. Al efecto, se postula la atipicidad de la desobediencia (como también de cualquier otra medida de protección desobedecida) cuando el incumplimiento que se pretende sancionar no corresponda a una contravención de una pena accesoria impuesta en sentencia definitiva, indicando, derechamente, que atendido el carácter de ultima ratio y subsidiario del derecho penal, el artículo 240 del Código de Procedimiento Civil, no es aplicable al auto motivado que decrete la cautelar, al ser este esencialmente modificable si se constata la desaparición de la motivación que originó la necesidad de cautela. También se postula la atipicidad del delito sosteniendo -como ya antes se ha expuesto- que nuestro Código Procesal Penal en el artículo 141 prevé un procedimiento subsidiario en caso de incumplimiento de medidas cautelares que puede ser analógicamente aplicable si esta ha sido impuesta conforme lo dispuesto en el artículo 15 de la ley 20.066, en relación al artículo 7 del mismo cuerpo legal. El fundamento de esta interpretación analógica se encontraría en que no deja ser la medida una cautelar personal cuyo incumplimiento podría sancionarse bajo la norma establecida en el artículo 141 del Código Procesal Penal.

No obstante, hay razones de texto expreso consagrados en el artículo 10 de la ley 20.066, así como en el artículo 94 de la ley 19.986 para rechazar tales argumentaciones, por cuanto las normas allí indicadas consagran el delito de desacato en relación al incumplimiento de una resolución que no es una sentencia definitiva, sino

28 Cfr., últimamente, Sentencia Corte de Apelaciones de San Miguel, de fecha 21 de abril de 2011, causa RIT N³72-2011.

29 Sentencia Tribunal de Juicio Oral en lo Penal de Iquique, de fecha 16 de mayo de 2007, causa RUC $N^{\circ}$ 0600153038-9, RIT N 61-2007. 
que más bien la de una medida cautelar de protección cuya naturaleza jurídica es la de un auto que persigue, entre otra, a la finalidad garantizar el derecho de la víctima a no sufrir nuevos ataques del mismo agresor contra su dignidad personal o integridad física ${ }^{30}$. Al efecto, se considera que la mayor protección de las víctimas de esta clase de violencia constituye un fin suficientemente relevante para justificar que del incumplimiento de esta clase de medidas cautelares se derive, además, la comisión del delito de desacato.

Además del elemento objetivo dado por la existencia de una medida cautelar o de protección o pena accesoria en un proceso y la vigencia de la prohibición que la impone, requiere un incumplimiento de una manera consciente y voluntaria por el imputado de incumplir la medida impuesta. A saber, el delito de desacato es eminentemente doloso, de forma que el autor ha de tener conciencia y voluntad de incumplir la medida impuesta. Al efecto, el dolo debe entenderse aquí como el conocimiento de la prohibición judicial y de las consecuencias de su incumplimiento (elemento cognoscitivo) y a pesar de ello, la voluntad de incumplirla (elemento volitivo). Así las cosas, existiendo conciencia y voluntad de su vulneración, no es necesario que el sujeto actúe motivado por la persecución de ningún objetivo en particular o manifestando una especial actitud interna. En este orden de ideas la búsqueda por el autor de otros fines últimos (ver a los hijos, asearse, comer, etc.) constituyen el "móvil", distinto por tal del dolo e irrelevantes para la existencia y configuración este delito de desacato.

Esta argumentación excluiría la comisión del ilícito de desacato cuando no existe dolo o no hay intencionalidad del agente de desobedecer la orden de alejamiento. Por ejemplo, cuando se produce por encuentros fortuitos o casuales entre el agresor y la víctima, sean estos fugaces y con mínimos contactos visuales.

Ahora bien, en lo referente a las formas de autoría y participación, solo puede ser autor del tipo del art. 240 Código Penal la persona sentenciada a la pena accesoria de alejamiento o sujeta a la medida cautelar o de protección de la misma naturaleza. Ello ha conllevado su calificación, por una parte de la doctrina, como delito de propia mano ${ }^{31} \mathrm{y}$, por otra, como un delito especial propio ${ }^{32}$. Aunque ambas calificaciones suponen una limitación de la autoría conviene poner de relieve que, mientras

30 En este punto resulta ilustrativa la Sentencia del Tribunal Supremo español 369/2004, de 11 de marzo, donde indica que aun tratándose en puridad de penas, las prohibiciones del artículo 48 del Código Penal participan del fundamento de las medidas de seguridad, o de protección, en cuanto encaminadas a proteger a la víctima del peligro abstracto de reiteración delictiva y evitar la reproducción de situaciones de proximidad personal o de comunicación entre los sujetos que pudieran propiciar tal reiteración $\mathrm{u}$ otros incidentes.

31 V. Córdoba Roda, Comentarios, p. 2330; González Rus, en Cobo del Rosal (coord.), Derecho Penal, p. 971; Manzanares Samaniego /en/ Serrano Butragueño (et al.), Delitos, p. 253.

32 V. Mestre Delgado /en/ Lamarca Pérez (coord.), Derecho Penal, 3ª ed., Cólex, p. 640. 
en los delitos de propia mano la restricción opera respecto a las clases de autoría (solo cabe la autoría directa), en los delitos especiales se trata de la delimitación de los sujetos que pueden ser autores (los intranei). La cuestión es, pues, cómo solucionar los casos de intervención de otros particulares (no directamente obligados) en la desobediencia de la prohibición; aunque la discusión es amplia, al menos parece claro que el extraneus no debiera ser castigado con la pena prevista en la ley para el autor.

De esta forma el incumplimiento de la medida de alejamiento puro u ordinario, es decir, en el que no hay consentimiento de la víctima, a mi modo de ver se satisface con la acreditación de una resolución judicial que acuerde el alejamiento (sea como medida cautelar o de protección sea como pena accesoria); firmeza o ejecutoriedad de tal resolución (en caso de pena accesoria, no de medida cautelar o de protección, puesto que precisamente, mantiene como finalidad mitigar y evitar la situación de riesgo de la víctima); notificación fehaciente de está al obligado ${ }^{33}$, y requerimiento de abstenerse de realizar la conducta prohibida; la conducta objetiva del incumplimiento, esto es, la vulneración de la prohibición, acercándose a la víctima a distancia no permitida por la resolución judicial; y, un dolo, esto es, conciencia y voluntad de querer incumplir la prohibición impuesta.

La desobediencia de la prohibición de alejamiento consentido, tolerado y aceptado por la víctima; relevancia jurídica de la voluntad de aproximación de la víctima.

Aun cuando se verifiquen los presupuestos antes anotados, se observa una desaplicación del delito de desacato en aquellos casos donde pese a ser notorio y evidente el quebrantamiento de la medida de alejamiento acordado, ya sea como pena accesoria de una condena o como una medida cautelar o de protección regulada por la ley 19.968, este se produce con el consentimiento o la tolerancia de la víctima.

Nos encontramos así con una creciente disposición judicial y administrativa ${ }^{34}$, que sin mayores disquisiciones se está otorgando a la voluntad de la víctima de reanudar la convivencia con el agresor, la relevancia jurídica suficiente como para dejar sin efecto la orden judicial de alejamiento dotando a estas medidas de un carácter disponible. Esta discutible práctica está acarreando no pocos problemas en el tratamiento jurídico y social de la violencia intrafamiliar y sus consecuencias.

33 No está de más señalar además "...con apercibimiento de que incurra en responsabilidad penal en caso de incumplimiento de la obligación fijada".

34 Hago referencia a salidas alternativas al proceso, como son archivos provisionales y decisiones de no perseverar. 
Efectivamente, alguna tendencia jurisprudencial y las cada vez más crecientes decisiones administrativas del Ministerio Público demuestran a ciencia cierta las posibles interpretaciones que puede suscitar el quebrantamiento de una medida de alejamiento cuando esta es consentida por la propia víctima con la intención de reanudar la convivencia con su agresor.

No obstante, la discusión está latente y existen discrepancias jurisprudenciales notorias.

A modo de ejemplificar lo que he vendido señalando, es ilustrativa la sentencia RIT 2157-2009, RUC 0900118086-7, seguida por el delito de desacato y lesiones, del Juzgado de Garantía de la ciudad de Toltén, en cuanto absolvió a un acusado por el delito de desacato que quebrantó una pena accesoria de prohibición de acercarse a su conviviente y al domicilio de esta estando debidamente notificado y en conocimiento de la decisión judicial, fundado -como se advierte de la sentencia- en el consentimiento que prestó la víctima al reanudar convivencia con su agresor. Al efecto, C.A.H.Ñ. fue denunciado por su conviviente N.A.S.C. por el delito de lesiones leves provocadas en contexto de violencia intrafamiliar. Como consecuencia de dicha denuncia y en el marco de las diligencias investigativas tendientes a acreditar el delito de lesiones, la policía detuvo al presunto agresor al ser descubierto infraganti -por cuanto lo encontraron en la morada de la víctima- incumpliendo una pena accesoria dictaminada en otra pasada causa anterior por violencia intrafamiliar entre ambas partes, donde precisamente se le prohibía aproximarse a la víctima y al domicilio que servía de hogar común de ambos. Celebrada la respectiva audiencia, quedó probado en primer lugar que el acusado, a pesar de la medida de alejamiento ordenada, se había trasladado a vivir al hogar que servía de hogar con su conviviente con el consentimiento de esta última por cuanto habían reanudado convivencia. Y en segundo lugar, resultó probado que en esta nueva convivencia el acusado agredió a la víctima en contexto de violencia intrafamiliar, dando lugar con ello a la denuncia que motivó el proceso.

Frente a esta situación, el juez decidió condenar al acusado por el delito de lesiones menos graves en contexto de violencia intrafamiliar, pero en cambio, decidió absolverlo por el delito de desacato señalando, entre otros argumentos, que no hubo quebrantamiento de la medida de alejamiento, indicando "...no se ha allegado ningún antecedente de investigación que dé cuenta que la voluntad de la víctima haya estado coaccionada o forzada para reanudar convivencia e interacción con su agresor...".

A fin de ilustrar la otra posición jurisprudencial que existe al respecto, en cuanto a considerar irrelevante el consentimiento de la mujer en el incumplimiento de la orden de alejamiento, se descubre en la sentencia RIT N 7-2009, RUC 0800664923-9, de la Ilustrísima Corte de Apelaciones de Coyhaique que anuló la sentencia y juicio 
oral recaía en el proceso RIT O-81-2008, del Juzgado de Garantía de Puerto Aysén ${ }^{35}$ indicando que la sentencia de la juez a quo ha incurrido en una errónea aplicación del derecho al dejar de aplicar la sanción establecida en el artículo 240 del Código de Procedimiento Civil cuando resultó acreditado, en el juicio, el incumplimiento por el acusado de la medida de alejamiento impuesto en su contra como medida cautelar de protección. Al efecto, el Tribunal de alzada acogiendo el recurso de nulidad interpuesto por el Ministerio Público fundado en la causal de nulidad prevista en el artículo 373 letra B) del Código Procesal Penal ${ }^{36}$, en lo que nos importa señaló: "(...) cabe consignar que lo que el legislador protege con las medidas cautelares es a la víctima de violencia intrafamiliar, de impredecibles consecuencias, y por ello el respeto y acatamiento de la prohibición de una determinada conducta - cuyo es el caso de autos- es relevante para cautelar el imperio del derecho (sic), a fin de no frustrar la finalidad perseguida por la medida cautelar, por ello, es totalmente inidóneo el posterior acuerdo que la víctima y el denunciado (sic) pueden prestar para poner fin a un proceso sobre violencia intrafamiliar o a una medida cautelar decretada (...) tratándose de resoluciones que prohíben una determinada conducta, cuando una persona igualmente lleva a cabo sus designios quebrantando la prohibición, tal conducta que ha sido vedada encuentra su sanción, en el caso específico que se examina, en el artículo 240 del Código Procesal Penal".

En este mismo orden de ideas, sentencias más recientes ${ }^{37}$ siguen esta línea argumentativa en cuanto sostener que para la configuración del ilícito de desacato del artículo 240 del Código de Procedimiento Civil, en lo que dice relación al incumplimiento de la orden de alejamiento, basta solo con acreditar, además de la existencia de la orden, la desobediencia de la misma, por cuanto tal ilícito se comete por el solo hecho de quebrantar lo ordenado cumplir por una resolución judicial. Al efecto, concluyen que por el hecho de incumplir una resolución judicial se afecta el bien jurídico protegido con la norma del artículo 240 inciso $2^{\circ}$. del Código Procesal Penal, esto es, "la correcta administración de justicia y el efectivo imperio de las resoluciones judiciales". No obstante, son estas mismas sentencias que dan a este ilícito una particularidad distinta, en cuanto señalan que el castigo del incumplimiento de la medida de alejamiento, con el delito de desacato, responde a uno de los objetivos buscados por la ley 20.066 y 19.968 , en cuanto prevenir, sancionar y erradicar la violencia intrafamiliar y otorgar protección a las víctimas de la misma, imponiéndosele la adopción de las medidas conducentes para garantizar la vida, integridad personal y seguridad de los miembros de la familia.

35 Entre otros argumentos, decidió absolver al encartado estimando que el mero incumplimiento de una medida de cautelar no lleva ipso facto aparejado el delito de desacato, ya que este tiende a la protección de la víctima física y síquica de la persona, lo que en la especie, nunca se sintió en riesgo o peligro o amenaza.

36 Artículo 373. Del recurso de nulidad. Procederá la declaración de nulidad del Juicio oral y de la sentencia: (...) b) Cuando, en el pronunciamiento de la sentencia, se hubiere hecho una errónea aplicación del derecho que hubiere influido sustancialmente en lo dispositivo del fallo.

37 Sentencia RIT N³72-2011, RUC 0901113826-5, de fecha 21 de abril de 2011 y RIT № 273-2011, de fecha 10 de enero de 2011, ambas de la Ilustrísima Corte de Apelaciones de San Miguel. 
Indudablemente, el problema es complejo de abordar por cuanto las posiciones son dispares y enfrentadas.

Hacía una reinterpretación judicial del delito de desacato en materia de violencia intrafamiliar.

Cualquiera sea la posición que se adopte debe partir por considerar que la naturaleza jurídica o el núcleo mismo de la medida de alejamiento impuesta durante el proceso sobre violencia doméstica tiene una naturaleza jurídica híbrida por cuanto persigue finalidades distintas y con efectos en varios ámbitos del proceso. En efecto, esta puede ser calificada como una medida cautelar personal por cuanto directamente, en su esencia, es un instrumento que restringe verdaderamente derechos fundamentales del imputado al verse limitada su libertad de desplazamiento y circulación con su imposición, especialmente, los sitios a los que puede acudir así como las personas con las que se relaciona, $y$, asimismo, la orden de alejamiento persigue proteger a la víctima del peligro de reiteración de agresiones similares y de evitar la reproducción de situaciones de proximidad personal entre el agresor y la ofendida que pudieran propiciar tal reiteración u otros incidentes.

Este núcleo de la medida de alejamiento no puede ser indiferente al momento de derivar -de su incumplimiento- el delito de desacato del artículo 240 inc. $2^{\circ}$. del Código Procedimiento Civil, toda vez que en este caso en particular el ilícito mantiene características que lo convierten en un delito pluriofensivo al tutelar dos bienes jurídicos complementarios: uno de naturaleza institucional, centrado en el adecuado funcionamiento del sistema institucional de Justicia y el efectivo imperio de las resoluciones judiciales; y otro de naturaleza personal, ceñido a la tutela de la indemnidad de la persona o personas cuya seguridad vital se protege. En efecto, el castigo tan severo a los incumplimientos de las penas accesorias y medidas cautelares de protección responde al objetivo programático de la ley 20.066, donde se señala el deber del Estado a "adoptar medidas conducentes para garantizar la vida, integridad personal y seguridad de los miembros de la familia" (art. 2 de la ley 20.066), el cual, y de acuerdo a la opinión de la Cámara Revisora de la ley Sobre Violencia Intrafamiliar en el seno legislativo, no es solo una repetición de la norma constitucional del inciso $5^{\circ}$. del artículo $1^{\circ}$, sino que tiene por objeto la adopción del sistema de medidas concretas en este sentido ${ }^{38}$. Así para plasmar esta finalidad ${ }^{39}$, el sistema normativo de la violencia intrafamiliar contempla penas o medidas accesorias (art. 9 de la ley 20.066) y medidas cautelares (art. 92 ley 19.968). Con ello, se entiende, se explicaría el hecho

38 Informe de la Comisión de Familia sobre las enmiendas introducidas por el Senado al proyecto de ley que introduce modificaciones en la ley 19.325 , que establece normas sobre procedimientos y sanciones relativos a los actos de violencia intrafamiliar (boletín $N^{\circ}$ 2318-18-3; informe 8540).

39 Carrasco Jiménez, Edison, Manual de Legislación Sobre Violencia Intrafamiliar, Librotecnia, Santiago de Chile. 2008. p. 53. 
de que la pena prevista para estos incumplimientos sea tan grave -incluso en los casos de quebrantamiento de una medida cautelar- como la prevista en el artículo 240 inciso $2^{\circ}$. del CPC.

De tal forma mediando el consentimiento del incumplimiento de la medida de alejamiento de la persona en cuyo favor se impuso no puede decirse que se haya atentado contra uno de los bienes jurídicos que constituyen el fin último de protección de la norma punitiva, esto es, la seguridad y tranquilidad de la víctima. Ciertamente que el desvalor de la acción es menor, cuestión que necesariamente deben incidir en la valoración del grado de la antijuridicidad material del caso concreto.

Este razonamiento lleva asumir que el consentimiento del incumplimiento de la orden de alejamiento tiene relevancia como un elemento negativo del tipo en el delito de desacato del artículo 240 del Código de Procedimiento Civil, cuando se trata de la vulneración de una medida cautelar durante el proceso. Así las cosas, el ilícito solo se configura si el incumplimiento no va acompañado de la voluntad de la víctima de renunciar a la protección que le otorga la medida. De lo contrario, ella se transformaría en una privación al ejercicio de la libertad y una arbitraria intromisión en la vida privada de las personas al decidirse con quiénes ellas deben estar.

Máxime si consideramos que en el alejamiento impuesto como medida cautelar de protección -no como pena- claramente no hay un ejercicio del ius puniendi del Estado, sino únicamente se pone en marcha un sistema de protección de la víctima. En este campo, el consentimiento tiene eficacia real, puesto que si se solicitó una medida de protección ante una situación de riesgo, cuando este cesa, también es lógico que dependa de la beneficiaria determinar si desea o no continuar compartiendo su vida con aquel a quien acusó de maltrato, sin que el Estado pueda obligar a esa pareja a vivir separados. Por otro lado, como toda medida cautelar penal, requiere la apreciación del Ilamado periculum in mora o necesidad de la medida para la protección de la víctima por ceñirse sobre ella un riesgo serio derivado de la cercanía con el agresor o imputado; así el artículo $7^{\circ}$ de la ley 20.066 y artículo 92 de la ley 19.968 cuando hablan "Cuando exista una situación de riesgo inminente para una o más personas de sufrir un maltrato constitutivo de violencia intrafamiliar..." o "Medidas cautelares en protección de la víctima. El juez de familia deberá dar protección a...", pudiendo ser modificadas cuando desaparezcan las circunstancias que se tomaron en consideración para adoptarlas, desapareciendo entonces la medida. Más aún, en la imposición del alejamiento impuesto como medida cautelar de protección, resulta de sentido común conocer la opinión de la víctima sobre su necesidad, pues si ella entiende que el peligro o riesgo no existe, no podría de dejarse de tener en cuenta dicha manifestación para su apreciación, aunque su opinión no sea vinculante. Es por ello, que la realidad que implica la renuncia tácita a la protección que proporciona el alejamiento, permitiendo el acercamiento del imputado o bien propiciando ella misma dicho acercamiento, en la mayoría de las ocasiones debe tener un necesario reflejo en la configuración del tipo penal de desacato.

170 Revista Chilena de Derecho y Ciencia Política - ISSN Impreso: 0718-9389 / ISSN on line: 0719-2150 
En apoyo a esta tesis en cuanto a otorgar relevancia del consentimiento de la mujer en el quebrantamiento de la medida de alejamiento impuesto como medida cautelar de protección y no existir delito por falta de tipicidad, se ha pronunciado el Tribunal Supremo español en su sentencia ${ }^{40}$ de fecha 26 de septiembre 2005, número 156/2005, recurso 781/2004, que se absolvió al acusado frente al quebrantamiento consentido de la víctima de una medida de protección judicialmente impuesta, por cuanto se estimó que resultaba ser la decisión más prudente y compatible con la naturaleza pública de la medida, dando seguridad jurídica a la persona en cuya protección se expida, al tiempo que respetaba el marco inviolable de su decisión libremente autodeterminada.

Ahora bien, considerar el consentimiento del incumplimiento de la orden de alejamiento como relevante en la tipicidad del delito de desacato cuando la prohibición de aproximación viene dada como pena accesoria en sentencia firme anterior, no resulta pacífico, al ser, el supuesto valorativo, distinto a la de una medida cautelar de protección. Al efecto, la imposición de la pena accesoria de alejamiento supone un enjuiciamiento definitivo del hecho y la determinación instaurada de la peligrosidad potencial del agresor para la víctima. Cuesta así entender que el perdón de la beneficiaria de la medida exima al sentenciado del cumplimiento de la pena. Más aún, ¿la situación de peligro de la víctima podría condicionar el cumplimiento efectivo de las penas hasta convertirlas en disponibles y con ello materializar una suerte de cesión de ius puniendi del Estado?, posición difícil de asumir desde las modernas concepciones de un Estado social y de derecho.

A modo de demostrar la falta de univocidad de criterios, es ilustrativa la posición del Tribunal Supremo español contraria a dar eficacia al consentimiento para excluir el delito de quebrantamiento cuando el alejamiento desobedecido fue impuesto como pena. Al efecto, en su sentencia ${ }^{41}$ 775/2007, de 28 de septiembre, re-

$40 \quad$ “(...) Podemos concluir diciendo que en cuanto la pena o medida de prohibición de aproximación está directamente enderezada a proteger a la víctima de la violencia que pudiera prevenir de su anterior conviviente, la decisión de la mujer de recibirle y reanudar la vida con él, acredita de forma fehaciente la innecesariedad de protección y, por tanto, supone de facto el decaimiento de la medida de forma definitiva, por lo que el plazo de duración de la medida fijado por la autoridad judicial, quedaría condicionado a la voluntad de aquella, sin perjuicio de que ante un nuevo episodio de ruptura violenta pueda solicitarse del juzgado, si es preciso para la protección de su persona, otra resolución semejante". Concluye la sentencia indicando "...una aplicación de lo expuesto al caso de autos lleva a la conclusión de que en el presente caso se ha objetivizado una duda en la propia sentencia acerca de sí con posterioridad al otorgamiento del auto de prohibición de aproximación, se volvió o no a convivir, lo que proyecta al menos una duda seria y razonable sobre el núcleo del tipo penal; el mantenimiento de la voluntad de la ex compañera de que el recurrente no se le acercara (sic), basta y sobra en esta situación para estimar que no ha existido quebrantamiento de medida, ni por tanto delito del artículo 468 CP..."

${ }^{41}$ Se analiza si existe delito del artículo 468.2 del CP cuando el alejamiento previamente impuesto como pena en sentencia anterior es incumplido al haber reanudado víctima y agresor de común acuerdo la 
curso 10037/2007, el Tribunal Supremo -en lo atingente- resolvió: ..." una cosa es el incumplimiento de una medida de seguridad que, en principio, sólo puede aplicarse a petición de parte y cuyo cese incluso podría acordarse si ésta lo solicitase al juez que además tiene por objeto, obviamente, una finalidad meramente preventiva, y más aún incluso cuando, además, no diere lugar posterior a la producción de ninguno de los ilícitos que precisamente pretendía impedir, y otra, muy distinta, aquella situación como la presente, en la que, aun contando con la aceptación de la protegida, se quebranta no una medida de seguridad, sino una pena ya impuesta y cuyo cumplimiento no es disponible por nadie, ni aun tan siquiera por la propia víctima, cuando además se propicia, con ese incumplimiento la comisión de hechos tan graves como los aquí enjuiciados".

Como puede observarse uno de los argumentos centrales para negarle relevancia al consentimiento del quebrantamiento de la medida de alejamiento, viene dado por negarle a la víctima o beneficiaria de la medida, la facultad para dejar sin efecto una pena impuesta por el carácter indisponible de la sanción. Ciertamente que ello dependerá de la posición que se adopte en cuanto a considerar que tan titular es la víctima del bien jurídico protegido por la norma punitiva que sanciona el incumplimiento de la prohibición de alejamiento. En efecto, no podrá existir lesión alguna del bien jurídico cuando una acción se basa en una disposición de su portador ${ }^{42}$ que no menoscaba su desarrollo, sino que, por el contrario, constituye su expresión. La voluntad de la víctima de reanudar la convivencia con su agresor en el ejercicio de su capacidad de autodeterminación y del derecho "a vivir juntos" con su pareja. Por el contrario, si habrá afectación del bien jurídico al considerar que la justificación de la sanción del incumplimiento viene dado en el resguardo a los individuos por el Estado de garantizarles una pacífica y ordenada convivencia social, independiente de la voluntad de la víctima manifestada en este sentido.

La discusión en este punto gira entre el interés del Estado en mantener la efectividad del sistema punitivo y el derecho de las personas tuteladas al ejercicio de posibilidades de actuación que contribuyen al pleno desarrollo de su personalidad. Nuevamente observamos colisión de dos bienes jurídicos; uno, de naturaleza institucional, y el otro, de naturaleza personal. ¿Cuál ha de preferirse entonces para una sana interpretación de la norma si hay consentimiento en el incumplimiento de la pena accesoria de alejamiento?, ciertamente aquel que socialmente produce algo más provechoso o al menos no se produce un daño social jurídico penalmente relevante $^{43}$, criterio a que necesariamente deberá acudirse en la ponderación judicial de

convivencia o, por el contrario, si resulta aplicable la STS de 26 de septiembre de 2005 y procedía por tanto la absolución por el delito de quebrantamiento.

42 Eser, Albin, Sobre la exaltación del bien jurídico a costa de la víctima, Universidad Externado de Colombia, Bogotá, 1998.

43 Claus Roxin, Derecho Penal, parte general, Civitas, Madrid, España, 1997, p. 556.

172 Revista Chilena de Derecho y Ciencia Política - ISSN Impreso: 0718-9389 / ISSN on line: 0719-2150 
los bienes jurídicos en conflicto. De tal forma resultaría irracional obligar irremisiblemente a las personas cuyo distanciamiento se dispuso por condena cuando se ha producido una verdadera restauración de la relación. Ciertamente que ello carecería de utilidad pública atendible y se convertiría por lo mismo en una medida aflictiva arbitraria suponiendo una intromisión del sistema penal intolerable en la privacidad de la pareja cuyo derecho más relevante es el derecho a vivir juntos. Más aún si la finalidad perseguida por la pena se ha conseguido, y en cambio, la continuación de su ejecución ya no estaría legitimidad por la consecución de su finalidad principal aseguradora.

Cualquier intervención punitiva alcanza un grado intolerable de irracionalidad cuando pretende que el habitante use el bien jurídico solo en determinada forma; esta pretensión es propia de un Estado que no respeta la autonomía de la conciencia (la persona) ni el concepto personalista del derecho, sino de un derecho transpersonal que subordina al humano a metas trascedentes de su humanidad, es decir, idolátricas (la raza, la nación, el régimen) ${ }^{44}$.

En efecto, pretender tutelar un bien jurídico más allá de la voluntad de su titular es un pretexto para penar una acción no conflictiva, ni relevante penalmente, y por ende, es violatoria al principio de reserva de la ley penal.

De tal forma y a modo de no lesionar el principio de indisponibilidad de las sanciones penales, y atento a la visión más extendida acerca de la naturaleza de las mismas, el alejamiento o prohibición de acercamiento no podrá considerarse una pena. Al efecto, si la víctima puede disponer a voluntad sobre si el alejamiento se ejecuta o no, entonces no puede tener la naturaleza jurídica de una pena, en el mejor de los casos sería una medida de seguridad cuyo cometido preventivo especial trata de evitar futuros actos delictivos del afectado admitiendo una injerencia -lo vinculante o no del consentimiento de la víctima- para su limitación o término más amplia que los previstos para una sanción penal.

\section{Conclusiones}

Como lo indicara al comienzo de este trabajo, la aplicación práctica de la medida de alejamiento en violencia intrafamiliar y la cotidianidad de su incumplimiento, es una problemática que enfrentan a diario fiscales y jueces y a la que deben dar respuesta frente a una sociedad que cada día más se sensibiliza con la temática de la violencia de género y que pide cuenta respecto de las medidas adoptadas para prevenirla precisamente por las situaciones de inseguridad física por las que atraviesan las víctimas.

${ }^{44}$ Zaffaroni, Eugenio, Derecho Penal, parte general, Ediar, Argentina, 2002, p. 499. 
A la hora de establecer medidas penales para el control de la violencia de doméstica en el ámbito familiar, no pueden ignorarse los rasgos básicos que permitan precisar la particularidad de la violencia que padece la mujer a manos de su pareja, y especialmente la clase de relación entre el agresor y la víctima: relación sentimental o de convivencia, actual o de pasado, reciente, con o sin hijos. Tales características sin duda que deben tenerse en cuenta en el diseño de medidas de prevención extrapenales y programas políticos criminales.

La imposición de medidas cautelares y penas basadas en el alejamiento del agresor no pueden ni deben ser un instrumento o mecanismo de anulación de la voluntad de la víctima que parten de una imagen racional de la mujer maltratada. Se debe realizar un nuevo esfuerzo de comprensión que vaya más allá de la tutela que se ofrecería a una persona incapaz, reinterpretando esas medidas de protección de forma compatible con el respeto a su intimidad, derecho al que pertenece la libertad de crear, mantener, y poner fin a una relación sentimental. La lógica del castigo, desatendiendo cualquier otra demanda de la mujer, es el camino al abismo y no ha de extrañar que la mujer entienda que este sistema no la va a apoyar en lo que ella pretende conseguir, que es el cese de la violencia, no necesariamente una separación forzosa.

Una imposición de medidas de alejamiento precipitadas y no justificadas que significan una separación forzada, refuerzan la idea que la mujer maltratada es incapaz de tomar una decisión racional. En el momento de decidir tales medidas cautelares de protección o penas accesorias que necesariamente inciden sobre la vida íntima de la mujer deben introducirse mecanismos más flexibles, de forma que sea posible valorar cada caso de forma individual.

Conviene que la decisión sobre la imposición de la prohibición de acercamiento se tenga en cuenta la voluntad de la persona que se pretende proteger, aunque su opinión no sea vinculante y que se dote a la prohibición de un régimen flexible de modificación y levantamiento que permita valorar todas las circunstancias del caso a la hora de establecer la reacción penal adecuada al supuesto concreto y que dé opciones al cambio de la prohibición por otra durante la ejecución. Por ejemplo, no se puede meter en un mismo saco el quebrantamiento de una medida transitoria o provisional, impuesta en muchos casos con demasiada celeridad, y el quebrantamiento de una pena accesoria. 


\section{Bibliográfía}

Aldunate Lizana, Eduardo (ed.), Constitución Política de la República de Chile. Doctrina y Jurisprudencia, Thomson Reuters Punto Lex, Santiago de Chile, 2009.

Carrasco Jiménez, Edison, Manual de legislación sobre violencia intrafamiliar, Librotecnia, Santiago de Chile, 2008.

Faraldo Cabana, Patricia, Las penas de los delitos relacionados con la violencia de género. Especial referencia a la prohibición de aproximación y su quebrantamiento /en/ Puente Aba, Luz María (ed.) La respuesta penal a la violencia de género. Lecciones de diez años de experiencia de una política penal punitivista, Comares, Granada, España, 2010.

Fuentes Soriano, Olga, El enjuiciamiento de la violencia de género, lustel, Madrid, España, 2009.

Laurenzo Copello, Patricia, La violencia de género en la ley, Dykinson, Madrid, España, 2010.

LoRente Acosta, Miguel, Mi marido me pega lo normal: agresión a la mujer, realidades y mitos, Crítica, Barcelona, 2001.

Mestre Delgado, Esteban, Delitos contra la Administración de Justicia /en/ Lamarca Pérez, C. (coord.), Derecho penal. Parte especial, $3^{\text {a }}$ ed., Madrid, España, 2005.

Montaner Fernández, Raquel, El quebrantamiento de penas o medidas de protección a las víctimas de la violencia doméstica. ¿Responsabilidad penal de la mujer que colabora o provoca el quebrantamiento? /En/ Dret, Universitat Pompeu Fabra, vol. 4/2007, Barcelona, España.

REVISTA PROCESAL PENAL, No 59, mayo 2007.

Roxın, Claus, Derecho Penal, parte general, Civitas, Madrid, España, 1997.

Villacampa Estiarte, Carolina, Stalking y Derecho Penal. Relevancia jurídico penal de una nueva forma de acoso, lustel, Madrid, España, 2009.

Walker, Eleonore, The Battered Woman, Springer, New York, United States, 1984.

ZafFARONI, Eugenio, Derecho penal, parte General, Ediar, Argentina, 2002. 